FEDERAL RESERVE BANK OF SAN FRANCISCO

WORKING PAPER SERIES

\title{
The Role of Capital Service-Life in a Model with Heterogenous Labor and Vintage Capital
}

\author{
Milton H. Marquis \\ Florida State University \\ Wuttipan Tantivongy \\ Florida State University \\ Bharat Trehan \\ Federal Reserve Bank of San Francisco
}

October 2009

Working Paper 2009-24

http://www.frbsf.org/publications/economics/papers/2009/wp09-24bk.pdf

The views in this paper are solely the responsibility of the authors and should not be interpreted as reflecting the views of the Federal Reserve Bank of San Francisco or the Board of Governors of the Federal Reserve System. 


\title{
The Role of Capital Service-Life in a Model with Heterogenous Labor and Vintage Capital
}

\author{
Milton H. Marquis, Wuttipan Tantivong†, and Bharat Trehan
}

October 9, 2009

\begin{abstract}
We examine how the economy responds to both disembodied and embodied technology shocks in a model with vintage capital. We focus on what happens when there is a change in the number of vintages of capital that are in use at any one time and on what happens when there is a change in the persistence of the shocks hitting the economy. The data suggest that these kinds of changes took place in the U.S. economy in the 1990s, when the pace of embodied technical progress appears to have accelerated. We find that embodied technology shocks lead to greater variability (of output, investment and labor allocations) than disembodied shocks of the same size. On the other hand, a decrease in the number of vintages in use at any time (such as is likely to occur when the pace of technical progress accelerates) tends to reduce the volatility of output and also to differentiate the initial response of the economy to the two shocks.
\end{abstract}

Keywords: Vintage Capital; Embodied Technology; Disembodied Technology; Workforce Heterogeneity.

\footnotetext{
*Florida State University, e-mail:mmarquis@fsu.edu

${ }^{\dagger}$ Florida State University, e-mail:wt05@fsu.edu

${ }^{\ddagger}$ Federal Reserve Bank of San Francisco, e-mail:Bharat.Trehan@frb.sf.org
} 


\section{Introduction}

There is a substantial literature on the role played by technology shocks in driving business cycles and causing economic fluctuations. Traditional estimates of technology shocks were derived from Solow residuals, but over time researchers have come up with a number of refinements and alternatives. In a prominent contribution, Greenwood, Hercowitz and Krusell $(\mathrm{GHK}, 1997)$ focus upon investment-specific technological change. They conclude that about 60 percent of the growth in U.S. productivity over the 1950 to 1990 period can be attributed to capital-specific technological change. In a subsequent paper, GHK (2000) find that technological change specific to new investment goods is the source of about 30 percent of output fluctuations.

Cummins and Violante (2002) show that technological improvement in equipment and software (E\&S) accounts for an important fraction of postwar GDP growth and plays a key role in the productivity resurgence of the 1990s in the United States. They find that the average annual growth in the quality of E\&S is 4 percent over the postwar period, with a sharp acceleration in the 1980s that leads to an average annual growth rate of more than 6 percent in the 1990s. Most of the acceleration is due to a shift in investment expenditures towards computers, software, and communications equipment.

Fisher (2002) uses the neoclassical growth model to identify the effects of technology shocks on the US business cycle. The model includes two sources of technology shocks: neutral shocks, which affect the productivity of all capital goods uniformly, and investment-specific shocks. He finds that neutral technological change is relatively unimportant for explaining the business cycle, accounting for less than 10 percent of business cycle variation in hours worked, while investment-specific tech- 
nological change accounts for about 50 percent of this variation. Therefore, in total, technology shocks account for a significant fraction of the business cycle variation in hours worked.

Gilchrist and Williams (2000) and Benhabib and Hobijn (2001) have shown that a vintage capital model with undifferentiated labor is better able to reproduce important dynamic relationships in the economy than the standard RBC model. Marquis and Trehan (2007) construct a vintage capital model in which worker skills lie along a continuum and workers can be paired with different vintages of capital (as technology evolves) under a matching rule of "best worker with the best machine". They assume that there are 2 kinds of technology shocks. The first is an embodied technology shock which changes the productivity of the latest vintage of capital relative to earlier vintages. The second is a disembodied technology shock (TFP) which affects all vintages equally. The economy tends to respond differently to these two kinds of technology shocks. In a model with three vintages of capital, they find that permanent shocks to disembodied technology induce a strong wealth effect that reduces savings and induces a consumption boom while permanent shocks to embodied technology induce dominant substitution effects and an expansion characterized by an investment boom.

In this paper, we extend the model from Marquis and Trehan (2007) to examine how the effects of permanent technology shocks vary with the number of vintages of capital that exist in the model. We expect the number of vintages to play an important role in the propagation of shocks in technology-driven business cycle models. With a new vintage every period, the number of vintages in use at any time (and thus the service life of capital) will depend upon the pace of embodied technical progress. Faster embodied technical progress implies larger differences in productivity across 
vintages, which in turn means that older vintages will find it harder to compete with the new ones.

Empirical estimates of the average service life of an economy-wide measure of capital are hard to come by. However, we can get some data on the service lives of different kinds of capital goods at a point in time and then examine how the shares of various broad categories of capital have changed over time. Not surprisingly, the share of investment in capital goods with short service lives has been going up while relative investment in capital with long service lives has been falling. In 2004, the distribution of gross investment in the nonfarm business sector by major assets types was $70 \%$ in equipment, $23 \%$ in structures, and $7 \%$ in rental residential. The BEA estimated that software had a service life of either 3 or 5 years, with the shorter period referring to pre-packaged software. The latest estimates from the BEA show that nominal spending on software was $3.3 \%$ of total spending on equipment and software in 1970, 11.4\% in 1990 and 22.2\% in 2007. By contrast, spending on industrial equipment (which the BEA estimated-in 1997- to have a service life of 16 years) has fallen from $29.6 \%$ in 1970 to $22 \%$ in 1990 and to $17.6 \%$ in 2007 . Thus, even if we make the extreme assumption that there was no change in the service life of various kinds of capital, the service life of the average unit of capital would be declining over time because the mix of capital being used has shifted towards short-lived capital.

Following Marquis and Trehan (MT, 2007), we do not determine the number of vintages within the model; instead, we use an exogenous scrappage rule to fix the number of vintages. We compare two models. One model is calibrated to an economy with rapid improvements in technology (where technology becomes obsolete after 3 
years) and a second model that is calibrated to an economy where the obsolescence of technology is much slower (taking 12 years). We focus upon three issues that pertain to the nature of economic fluctuations. The first issue is how the economy responds to disembodied versus embodied technology shocks. The next issue is how the rate of obsolescence of technology alters the response of the economy to shocks. We ask this question by examining whether the number of vintages in the economy matters. The last issue concerns the persistence of the technological processes, that is we ask: Do highly persistent shocks qualitatively affect the manner in which the economy absorbs the shocks?

To analyze the above issues, we will examine how key macroeconomic variables, such as the consumption-output ratio, the saving rate, total aggregate hours worked, and the labor allocation, respond to an individual technology shock and to a sequence of technology shocks. Many economists believe that a sequence of embodied technology shocks, concentrated in the information technology area, occurred during the late 1990s and represented a principal causal factor in the pick up in growth rates of output and productivity. ${ }^{1}$

The remainder of the paper is organized as follows. In Section 2 we spell out the theoretical model of vintage capital with heterogenous labor. Section 3 presents the calibration of the model, shows values of parameters and the resulting steady-state values for the 3 and 12 vintage capital models. In Section 4 we compute the responses of the economy to disembodied and embodied technology shocks and compare the results for the 3 and 12 vintage capital models. We also conduct exercises in which the persistence parameters of the shock processes are varied and see what difference this

\footnotetext{
${ }^{1}$ See Oliner and Sichel (2007), for example.
} 
makes to the business cycle. The last section summarizes the findings and suggests directions for future research.

\section{Theoretical Model}

The model developed in this chapter is the similar to Marquis and Trehan (MT, 2007), but with the number of vintages of capital (each incorporating the latest technology from the previous year) increased to 12, representing a slower rate of obsolescence of technology than the 3-vintage model of MT. There is a distribution of workers across a skill continuum of measure one. Workers offer their labor services to an aggregate firm that operates multiple production processes that differ in the vintage of capital equipment used. The firm matches the highest skilled group of workers with the latest vintage of capital, and the next highest-skilled group with the second newest vintage capital, and so on. Hence the group of workers assigned to a given vintage of capital has workers that are close to one another in skill level. The matching rule is consistent with a rule which Jovanovic (1998) identifies as being both plausible and empirically well-founded. He suggests that new technologies and skills are complementary, so that new machines will be used by the most skilled workers. The next assumption is that the workers in the same group, that is, workers who work with the same vintage of capital, receive the same wage rate that reflects the average marginal product of the labor from the group.

Growth in the economy comes from two sources: Improvements in disembodied technology, which affect all production processes symmetrically, and improvements in embodied technology, which differentially affect productivity across production 
processes by determining the quality of the newest vintage. The number of vintages in the economy is assumed to be fixed, and enforced by an exogenous scrappage rule. The equilibrium schedule of prices for capital declines with vintage.

\subsection{Production with Vintage Capital and the Determinants of Growth}

Output in this economy can be produced from a number of production processes that are distinctly identified by the vintage of capital that they utilize. Each production process is affected by the same economy-wide disembodied technology, denoted $\mu_{t}$. We denote the vintage of capital employed by each production process by the index $j=1 \ldots T$, where $T$ is the number of vintages in the economy. The newest vintage of capital in production at date $t$ is represented by $K_{t}^{1}$ and the oldest vintage is $K_{t}^{T}$. The production function is given by:

$$
F\left(K_{t}^{j}, H_{t}^{j} ; \mu_{t}, A_{t-j}\right)=\mu_{t} \sum_{j=1}^{T}\left(K_{t}^{j}\right)^{\alpha}\left(A_{t-j} H_{t}^{j}\right)^{1-\alpha}, \quad \alpha \in(0,1), \quad j=1, \ldots, T
$$

where $A_{t-j}$ is the vintage-specific level of embodied technology that is matched with the total human capital, $H_{t}^{j}$, or quality-adjusted labor utilized in vintage $j$ at date t. We note here that fewer high-skilled workers are required to attain a given level of $H_{t}^{j}$ than would be the case for lower-skilled workers. Therefore, the total hours worked assigned to any particular production process depends on both embodied technological progress and the average skill level of a particular group of workers, whose composition is endogenously determined. 
There are two sources of long-run productivity growth: one is the gross growth rate of embodied technology $A_{t}$ that is represented by $\gamma_{t}$, with technological improvements given by:

$$
\gamma_{t-j}=\left(\frac{A_{t-j}}{A_{t-j-1}}\right), \quad j=1, \ldots, T
$$

The second source of growth is the gross growth rate of disembodied technology $\mu_{t}$, that is represented by $g_{t}$, or:

$$
g_{t}=\left(\frac{\mu_{t}}{\mu_{t-1}}\right)
$$

To render the model stationary, the variables were normalized as follows. The normalized capital stocks are denoted:

$$
\widetilde{K}_{t}^{j}=\left(\frac{K_{t}^{j}}{\Omega_{t-j}}\right), \quad j=1, \ldots, T
$$

where the newest vintage of capital is normalized on the current level of disembodied technology and the level of embodied technology associated with the oldest vintage of capital used in current production, that is:

$$
\Omega_{t-1}=\mu_{t}^{\frac{1}{1-\alpha}} A_{t-T}
$$

and the general form for any given vintage $j$ is:

$$
\Omega_{t-j}=\mu_{t-j+1}^{\frac{1}{1-\alpha}} A_{t-T-j+1}
$$


Hence the normalized production function is given by:

$$
\widetilde{F}\left(K_{t}^{j}, H_{t}^{j} ; G_{t-i}, \Gamma_{t-j}\right)=\sum_{j=1}^{T}\left(\frac{\widetilde{K}_{t}^{j}}{\Pi_{i=0}^{j-2} G_{t-i}}\right)^{\alpha}\left(\Gamma_{t}^{j} H_{t}^{j}\right)^{1-\alpha}, \quad \alpha \in(0,1), \quad j=1, \ldots, T
$$

where

$$
\widetilde{F}=\left(\frac{F}{\Omega_{t-1}}\right)
$$

and

$$
G_{t-i}=\left(\frac{\Omega_{t-i-1}}{\Omega_{t-i-2}}\right)
$$

with $\Pi_{i=0}^{-1} G_{t-i} \equiv 1$. The relative level of embodied technology between the $j$ th vintage of capital and the oldest ( $T$ th) vintage is given by:

$$
\Gamma_{t}^{j}=\left(\frac{A_{t-j}}{A_{t-T}}\right), \quad j=1 \ldots T
$$

Note that:

$$
\Gamma_{t}^{1}>\Gamma_{t}^{2}>\ldots \Gamma_{t}^{T}=1
$$

where $\Gamma_{t}^{j}$ can interpret as the "quality gradient" in capital across vintages. The more rapid is the pace of embodied technological progress, the steeper is the quality gradient.

Also, the gross growth rate of the economy at date $t$ is represented as $G_{t}$, which reflects both the disembodied and embodied technological progress:

$$
G_{t}=g_{t}^{\frac{1}{1-\alpha}} \gamma_{t-T}
$$




\subsection{Workforce Heterogeneity}

There are $P$ workers in the economy. Worker human capital is distributed uniformly along the unit interval that is indexed by $x$, with $x \in[0,1]$. The human capital of each worker with index $x$ is denoted by $h(x)$ where the most highly skilled workers have an index $x=0$ and a human capital level of $h(0)$, and the least-skilled workers have an index $x=1$ and a human capital level of $h(1)$. Each worker faces the time constraint $z_{t}+l_{t} \leq 1$, where $z_{t}$ is the fraction of time devoted to labor and $l_{t}$ is the fraction of time devoted to leisure. The household's total leisure time for all workers is given by $L_{t}=P l_{t}$. Hence, the total amount of time allocated to labor is:

$$
P z_{t}=P-L_{t}
$$

The total amount of human capital that is allocated to vintage $j$ is given by:

$$
H_{t}^{j}=P z_{t} \int_{x_{t}^{j-1}}^{x_{t}^{j}} h(x) d x=\left.P z_{t} \chi(x)\right|_{x_{t}^{j-1}} ^{x_{t}^{j}}=P z_{t}\left[\chi\left(x_{t}^{j}\right)-\chi\left(x_{t}^{j-1}\right)\right], \quad j=1, \ldots, T
$$

where $z_{t} \chi(x)$ is the cumulative distribution of human capital per capita employed at date t. The total number of hours worked by workers assigned to capital of vintage $j$ is given by:

$$
N_{t}^{j}=P z_{t} \int_{x_{t}^{j-1}}^{x_{t}^{j}} d x=P z_{t}\left[x_{t}^{j}-x_{t}^{j-1}\right], \quad j=1, \ldots, T
$$




\subsection{Household Optimization}

Households own the capital goods whose prices are determined as in Lucas (1978). The representative household selects contingent group employment decision rules by partitioning $x$ into $T$ worker groups of contiguous skill levels, denoted $\hat{x}_{t}^{j}=$ $x_{t}^{j}-x_{t}^{j-1}, j=1 \ldots T$ which determines the amount of quality-adjusted labor that is being offered to the firm. The precise partitioning of the workforce is an equilibrium outcome with firms setting demand schedules for human capital that is assigned to each vintage such that the matching rule of "best workers" with the "best machines" is enforced. The household also makes consumption-savings, labor-leisure, and capital asset portfolio allocation decisions. The household's optimization problem is:

$$
\max _{\left\{c_{t}, L_{t}, \widehat{x}_{t}^{j}, H_{t}^{j}, K_{t+1}^{j}\right\}} E_{0} \sum_{t=0}^{\infty} \beta^{t} U\left(c_{t}, L_{t}\right), \quad j=1, \ldots, T
$$

where $c_{t}$ is the household's consumption, $\left\{K_{t}^{j}\right\}_{j=1}^{T}$ is the household's capital holdings whose values are given at date $t=0$ when the optimization is conducted.

The household's budget constraint is:

$$
c_{t}+K_{t+1}^{1}+\sum_{j=1}^{T-1} p_{t}^{j} K_{t+1}^{j+1} \leq \sum_{j=1}^{T} R_{t}^{j} K_{t}^{j}+\sum_{j=1}^{T} W_{t}^{j} H_{t}^{j}+\sum_{j=1}^{T} p_{t}^{j}(1-\delta) K_{t}^{j}, \quad \delta \in(0,1)
$$

The household combines its capital income (where $R_{t}^{j}$ is the rental rate on a unit of the $j$ th vintage of capital), its labor income (where $W_{t}^{j}$ is the wage rate per unit of quality-adjusted labor-or human capital-assigned to the $j$ th production process) and the revenue from the sale of capital holdings (where $p_{t}^{j}$ is the market price of the $j$ th vintage of capital at date $t$ and $\delta$ is the depreciation rate) to purchase consumption 
and investment goods. Note that investment in the newest vintage capital, $K_{t+1}^{1}$, will be rented to the firm in period $t+1$.

The household's labor supply decisions are further constrained by its total available human capital and the matching rule, such that:

$$
H_{t}^{j}=P z_{t}\left[\chi\left(x_{t}^{j}\right)-\chi\left(x_{t}^{j-1}\right)\right], \quad j=1, \ldots, T
$$

and

$$
\sum_{j=1}^{T} \widehat{x}_{t}^{j}=\sum_{j=1}^{T}\left[x_{t}^{j}-x_{t}^{j-1}\right]=1
$$

The household also faces the time resource constraint that is:

$$
z_{t}+\frac{L_{t}}{P} \leq 1
$$

We normalize the household's problem with $\Omega_{t-j}$, and defining the normalized variables $\widetilde{c}_{t}=\left(\frac{c_{t}}{\Omega_{t-1}}\right)$ and $\widetilde{\varpi}_{t}^{j}=\left(\frac{W_{t}^{j}}{\Omega_{t-1}}\right)$, the Euler equations for the consumption-saving and the portfolio allocation decisions are:

$$
\beta E\left\{\left(\frac{U_{\widetilde{c}_{t+1}}}{U_{\widetilde{c}_{t}}}\right)\left[\frac{R_{t+1}^{j+1}+p_{t+1}^{j+1}(1-\delta)}{G_{t+1} p^{j}}\right]\right\}=1, \quad p_{t}^{0}=1, \quad j=0, \ldots,(T-1)
$$

These Euler equations take the form of asset pricing equations for the various vintages of capital. There is no investment in vintage $T$, since it is scrapped at the end of the period.

The wage rate paid per unit of human capital (quality-adjusted labor) is the same 
across all worker groups, that is:

$$
\widetilde{\varpi}_{t}^{j}=\widetilde{\varpi}_{t}^{j-1}, \quad j=1, \ldots, T
$$

The Euler equation for the labor-leisure decision for all workers is:

$$
U_{\widetilde{c}_{t}} \sum_{j=1}^{T} H_{t}^{j} \widetilde{\varpi}_{t}^{j}=z_{t} P U_{L_{t}}
$$

\subsection{Firm's Optimization}

The firm is assumed to be competitive in the factor and product markets. It hires quality-adjusted units of labor and rents physical capital of all vintages from households. The firm matches the most highly skilled workers with the latest vintage capital and pays the workers who are assigned to work on the same vintage capital the same wage. The firm chooses factor inputs to maximize profits period-by-period:

$$
\max _{K_{t}^{j}, H_{t}^{j}}\left[\mu_{t} \sum_{j=1}^{T}\left(K_{t}^{j}\right)^{\alpha}\left(A_{t-j} H_{t}^{j}\right)^{(1-\alpha)}-\sum_{j=1}^{T} R_{t}^{j} K_{t}^{j}-\sum_{j=1}^{T} W_{t}^{j} H_{t}^{j}\right], \quad j=1, \ldots, T
$$

The first-order conditions for the firm's problem set the rental rates on capital and labor equal to their marginal products of capital and labor:

$$
\begin{aligned}
& \alpha\left(\frac{\widetilde{K}_{t}^{j}}{H_{t}^{j}}\right)^{(\alpha-1)}\left(\prod_{i=0}^{j-2} G_{t-i}\right)^{(1-\alpha)}\left(\Gamma_{t}^{j}\right)^{(1-\alpha)}=R_{t}^{j}, \quad j=1, \ldots, T \\
& (1-\alpha)\left(\frac{\widetilde{K}_{t}^{j}}{H_{t}^{j}}\right)^{\alpha}\left(\prod_{i=0}^{j-2} G_{t-i}\right)^{-\alpha}\left(\Gamma_{t}^{j}\right)^{(1-\alpha)}=\widetilde{\varpi}_{t}^{j}, \quad j=1, \ldots, T
\end{aligned}
$$


Note that from the matching rule, the firm will wish to allocate more human capital to later vintages as they possess a higher level of embodied technology. This effect becomes more pronounced as the quality gradient steepens.

\subsection{Equilibrium}

Equilibrium in the goods market consists of transforming output goods along with the scrapped capital of vintage $T$, the sum of which is defined as normalized output, $\widetilde{y}_{t}$, into consumption and new investment, that is:

$$
\widetilde{c}_{t}+\widetilde{i}_{t}=\widetilde{y}_{t}=\sum_{j=1}^{T}\left(\frac{\widetilde{K}_{t}^{j}}{\prod_{i=0}^{j-2} G_{t-i}}\right)^{\alpha}\left(\Gamma_{t}^{j} H_{t}^{j}\right)^{1-\alpha}+p_{t}^{T}(1-\delta)\left(\frac{\widetilde{K}_{t}^{T}}{\prod_{i=0}^{T-2} G_{t-i}}\right)
$$

where $\widetilde{i}_{t}=G_{t+1} \widetilde{K}_{t+1}^{1}$ is the normalized investment. The undepreciated portion of the oldest vintage of capital is sold at the end of the period for a unit price of $p_{t}^{T}$ as determined by the exogenous scrappage rule, which is a linear projection of the equilibrium schedule of prices for vintages $T-1$ and $T-2$ :

$$
\frac{p_{t}^{T}}{p_{t}^{T-1}}=\frac{p_{t}^{T-1}}{p_{t}^{T-2}}
$$

The evolution of the normalized capital stocks is given by:

$$
\widetilde{K}_{t+1}^{j+1}=(1-\delta) \widetilde{K}_{t}^{j}
$$




\section{Calibration Issues}

To calibrate the model, we use the semi-log-linear utility function:

$$
U\left(\widetilde{c}_{t}, L_{t} ; \Omega_{t-1}\right)=\ln \left(\Omega_{t-1} \widetilde{c}_{t}\right)+\eta L_{t}, \quad \eta>0
$$

For the distribution of skills, we use an exponential function that fits well with the empirical distribution of human capital estimated by Abowd, Lengermann, and McKinney (2002). Their estimates are based on the Longitudinal Employer-Household Dynamics (LEHD) Program data for $1992 .^{2}$ The empirical model is:

$$
h(x)=S_{0} e^{\phi(1-x)}, \quad S_{0}, \phi>0
$$

where estimated values of $S_{0}=8.92$ and $\phi=2.187 .^{3}$

\subsection{Steady-State Model}

We perform two separate calibrations of the model. They differ by the number of vintages in use in production. In the first calibration, we choose $T=3$ vintages, reflecting an economy undergoing rapid technological advance. In the second calibration, we choose $T=12$ for an economy with relatively long-lived capital in use. For the (normalized) version of the model with three vintages of capital, there are 21 endogenous variables, $H^{j}, x^{j}, L, z, p^{j}, r^{j}, \widetilde{c}, \widetilde{K}^{j}, \widetilde{\varpi}^{j}, j=1, \ldots, 3$, where the net real

\footnotetext{
${ }^{2}$ These data cover California, Illinois, Michigan, and North Carolina for the 1st quarter, and include over 400,000 observations. See Abowd, Lengermann, and McKinney (2002), Table 9.

${ }^{3}$ The empirical model was estimated to be $L h c=9.21+0.0219 P e$, where $L h c$ demotes the log of the dollar value of human capital and $P e$ denoted the percentile of the human capital distribution. The equation had a p-value for $P e$ of .00001 and an adjusted- $R^{2}$ of 0.98 .
} 
rental rates on capital $\widetilde{K}^{j}$, are given by $r^{j}=R^{j}-\delta$. There are 4 exogenous variables, $\Gamma^{j}, G, j=1, \ldots, 3$; and 7 parameters, $A, \phi, \beta, \delta, \eta, \alpha, P$. We make the following selections. $S_{0}$ and $\phi$ are estimated as described above. Capital's share of income is set to $\alpha=0.33$. The depreciation rate is set $\delta=1 / T$, which implies a $\delta=0.333$. The population of workers is an exogenous scale variable in the model that is set to $P=100$. The annualized gross rate of the economy is set to $G=1.025$, of which 60 percent is attributed to embodied technological process, or $\Gamma^{j}=1.015, j=1, \ldots, 3$. The contribution of embodied technology to growth is consistent with Greenwood, Hercowitz, and Krusell (1997), Gilchrist and Williams (2000), and Wilson (2000) who estimate the contribution to lie within the range is of 50 and 70 percent. The discount factor is set $\beta=0.96$ for the annual calibration. We assume a 40-hour workweek $(z=0.36)$ which corresponds to a preference parameter on leisure in the utility function of $\eta=2.6456$. We can check that the average real net rental rate across the capita vintages is 7.52 or 7.84 (if capital weighted) ${ }^{4}$ - a value that is close to the long-run return on U.S. equities from 1889 to 2005 in Mehra and Prescott (2008).

For the 12 vintage capital case, there are 75 endogenous variables, $H^{j}, x^{j}, L, z, p^{j}$, $r^{j}, \widetilde{c}, \widetilde{K}^{j}, \widetilde{\varpi}^{j}, j=1, \ldots, 12$ and there are 13 exogenous variables , $\Gamma^{j}, G, j=1, \ldots, 12$; and 7 parameters, $A, \phi, \beta, \delta, \eta, \alpha, P$. All of the parameters have the same calibrated values as in the 3-vintage capital model, except the depreciation rate of $\delta=0.083$ $(\delta=1 / 12)$ that is close to reality and $\eta=2.4847$ for $z=0.36$. The average rental rate across the twelve vintages is 6.85 or 7.32 (when capital weighted).

Table 1 reports a summary of the parameters. Tables 2 and 3 report summaries of the steady-state values derived for the 3 - and 12-vintage capital models from the

\footnotetext{
${ }^{4}$ The capital-weighted real net rental rate is calculated by averaging the total rental rate of all vintages $\left(\sum R^{j} K^{j} / \sum K^{j}\right)$.
} 
calibration exercise that we use as the "benchmarks" in subsequent exercises.

Table 1: Benchmark Parameters

\begin{tabular}{cccc}
\hline \hline Parameters & $\begin{array}{c}\text { Benchmark } \\
\text { Values }\end{array}$ & Parameters & $\begin{array}{c}\text { Benchmark } \\
\text { Values }\end{array}$ \\
\hline$\alpha$ & 0.33 & $S_{0}$ & 8.92 \\
$\beta$ & 0.96 & $\phi$ & 2.187 \\
$\delta_{3}$ & $1 / 3$ & $\rho_{A, G H K}$ & 0.49747 \\
$\delta_{12}$ & $1 / 12$ & $\rho_{A, O R T H O}$ & 0.58146 \\
$\eta_{3}$ & 2.6456 & $\rho_{m}$ & 0.31420 \\
$\eta_{12}$ & 2.4847 & $\sigma_{A, G H K}$ & 0.00410 \\
$\bar{\gamma}$ & 1.015 & $\sigma_{A, O R T H O}$ & 0.00357 \\
$\bar{G}$ & 1.025 & $\sigma_{m}$ & 0.00303 \\
$P$ & 100 & & \\
\hline
\end{tabular}

Note: Subscripts 3 and 12 denote the parameters for the 3 and 12 vintage models. The subscript GHK means using the Greenwood, Hercowitz, and Krusell (1997) method for calculating technology change. The subscript ORTHO means using the Orthogonal Method, where we set the coefficient of Disembodied Technology equal to 0.4.

\subsection{Stochastic Model}

To solve the stochastic version of the model and run dynamic simulations, characterizations of the stochastic processes driving the two sources of productivity growth are needed. We assumed AR1 processes for each (as did Glichrist and Williams 2000), reflecting the fact that a time series on average productivity is well characterized by such a process. We use the relationship between productivity growth in the consumption goods sector and capital goods sector to capture the growth of embodied and disembodied technological processes (see Marquis and Trehan 2005). We perform two separate decompositions of aggregate productivity between embodied and disembodied technological processes. One decomposition is based on Greenwood, Hercowitz, and Krusell $(1997,2000)$ (GHK), which as described in Marquis and Trehan (2008) (MT), causes the disembodied (economy-wide) technology shock to be correlated with 
Table 2: Benchmark Steady-State Values for 3 Vintage Model

\begin{tabular}{cccc}
\hline \hline Variables & $\begin{array}{c}\text { Benchmark } \\
\text { Values }\end{array}$ & Variables & $\begin{array}{c}\text { Benchmark } \\
\text { Values }\end{array}$ \\
\hline$\widetilde{c}$ & 746.55 & $z$ & 0.36 \\
$\widetilde{i}$ & 420.27 & $\widehat{x}^{1}$ & 0.263 \\
$\widetilde{y}$ & 1166.82 & $\widehat{x}^{2}$ & 0.309 \\
$\widetilde{K}^{1}$ & 410.02 & $\widehat{x}^{3}$ & 0.428 \\
$\widetilde{K}^{2}$ & 273.35 & $N^{1}$ & 9.47 \\
$\widetilde{K}^{3}$ & 182.23 & $N^{2}$ & 11.11 \\
$r^{1}$ & $8.756^{*}$ & $N^{3}$ & 15.42 \\
$r^{2}$ & $7.503^{*}$ & $H^{1}$ & 572.23 \\
$r^{3}$ & $6.287^{*}$ & $H^{2}$ & 361.10 \\
$r_{\text {ave }}$ & 7.515 & $H^{3}$ & 227.87 \\
$r_{\text {ave }, w}$ & 7.840 & $\widetilde{v}^{1}$ & 37.00 \\
$p^{1}$ & 0.970 & $\widetilde{v}^{2}$ & 19.90 \\
$p^{2}$ & 0.941 & $\widetilde{v}^{3}$ & 9.05 \\
$p^{3}$ & 0.913 & & \\
\hline
\end{tabular}

Note: ${ }^{*}$ denotes percentage. The subscript ave denotes average values. The subscript $w$ denotes the capital weighted average of the real rental rate.

the embodied (capital-specific) technology shocks. As an alternative, MT obtain estimates of uncorrelated embodied and disembodied technology shocks by imposing theoretical restrictions on price data in a 2 -sector model. ${ }^{5}$

For both the GHK and MT (orthogonal) decompositions, we obtain the persistence parameters of the growth processes using data from 1965 to 2006 by estimating AR1 processes for disembodied technology $(\mu)$ and embodied technology $(A)$ as:

$$
\begin{array}{ll}
\ln g_{t}=c+\rho_{m} \ln g_{t-1}+\epsilon_{t}, & \rho_{m} \in[0,1), \quad \epsilon_{t} \sim N\left(0, \sigma_{m}^{2}\right) \\
\ln \gamma_{t}=c+\rho_{A} \ln \gamma_{t-1}+\nu_{t}, & \rho_{A} \in[0,1), \quad \nu_{t} \sim N\left(0, \sigma_{A}^{2}\right)
\end{array}
$$

\footnotetext{
${ }^{5}$ GHK's restriction allows the embodied technology shock to be represented by changes in the relative price of capital to consumption goods. MT rejects this restriction, and provides evidence that the economy-wide shock differentially affects productivity in the consumption goods and capital goods sectors.
} 
Table 3: Benchmark Steady-State Values for 12 Vintage Model

\begin{tabular}{cccccc}
\hline \hline Variables & $\begin{array}{c}\text { Benchmark } \\
\text { Values }\end{array}$ & Variables & $\begin{array}{c}\text { Benchmark } \\
\text { Values }\end{array}$ & Variables & $\begin{array}{c}\text { Benchmark } \\
\text { Values }\end{array}$ \\
\hline$\widetilde{c}$ & 1387.32 & $p^{1}$ & 0.970 & $N^{7}$ & 2.91 \\
$\widetilde{i}$ & 568.33 & $p^{2}$ & 0.941 & $N^{8}$ & 3.03 \\
$\widetilde{y}$ & 1955.66 & $p^{3}$ & 0.913 & $N^{9}$ & 3.17 \\
$\widetilde{K}^{1}$ & 554.47 & $p^{4}$ & 0.886 & $N^{10}$ & 3.35 \\
$\widetilde{K}^{2}$ & 508.27 & $p^{5}$ & 0.860 & $N^{11}$ & 3.59 \\
$\widetilde{K}^{3}$ & 465.91 & $p^{6}$ & 0.834 & $N^{12}$ & 3.92 \\
$\widetilde{K}^{4}$ & 427.08 & $p^{7}$ & 0.809 & $H^{1}$ & 187.86 \\
$\widetilde{K}^{5}$ & 391.49 & $p^{8}$ & 0.785 & $H^{2}$ & 163.00 \\
$\widetilde{K}^{6}$ & 358.87 & $p^{9}$ & 0.762 & $H^{3}$ & 141.43 \\
$\widetilde{K}^{7}$ & 328.96 & $p^{10}$ & 0.739 & $H^{4}$ & 122.72 \\
$\widetilde{K}^{8}$ & 301.55 & $p^{11}$ & 0.717 & $H^{5}$ & 106.48 \\
$\widetilde{K}^{9}$ & 276.42 & $p^{12}$ & 0.696 & $H^{6}$ & 92.39 \\
$\widetilde{K}^{10}$ & 253.38 & $\widehat{x}^{1}$ & 0.0709 & $H^{7}$ & 80.17 \\
$\widetilde{K}^{11}$ & 232.27 & $\widehat{x}^{2}$ & 0.0719 & $H^{8}$ & 69.56 \\
$\widetilde{K}^{12}$ & 212.91 & $\widehat{x}^{3}$ & 0.0731 & $H^{9}$ & 60.35 \\
$r^{1}$ & $9.500^{*}$ & $\widehat{x}^{4}$ & 0.0745 & $H^{10}$ & 52.37 \\
$r^{2}$ & $8.969^{*}$ & $\widehat{x}^{5}$ & 0.0763 & $H^{11}$ & 45.44 \\
$r^{3}$ & $8.454^{*}$ & $\widehat{x}^{6}$ & 0.0784 & $H^{12}$ & 39.43 \\
$r^{4}$ & $7.954^{*}$ & $\widehat{x}^{7}$ & 0.0809 & $\widetilde{v}^{1}$ & 78.66 \\
$r^{5}$ & $7.469^{*}$ & $\widehat{x}^{8}$ & 0.0841 & $\widetilde{v}^{2}$ & 69.29 \\
$r^{6}$ & $6.999^{*}$ & $\widehat{x}^{9}$ & 0.0881 & $\widetilde{v}^{3}$ & 57.43 \\
$r^{7}$ & $6.542^{*}$ & $\widehat{x}^{10}$ & 0.0932 & $\widetilde{v}^{4}$ & 48.87 \\
$r^{8}$ & $6.099^{*}$ & $\widehat{x}^{11}$ & 0.0998 & $\widetilde{v}^{5}$ & 41.44 \\
$r^{9}$ & $5.670^{*}$ & $\widehat{x}^{12}$ & 0.1088 & $\widetilde{v}^{6}$ & 34.99 \\
$r^{10}$ & $5.253^{*}$ & $N^{1}$ & 2.55 & $\widetilde{v}^{7}$ & 29.40 \\
$r^{11}$ & $4.848^{*}$ & $N^{2}$ & 2.59 & $\widetilde{v}^{8}$ & 24.55 \\
$r^{12}$ & $4.456^{*}$ & $N^{3}$ & 2.63 & $\widetilde{v}^{9}$ & 20.34 \\
$r_{a v e}$ & 6.851 & $N^{4}$ & 2.68 & $\widetilde{v}^{10}$ & 16.68 \\
$z$ & 7.320 & $N^{5}$ & 2.75 & $\widetilde{v}^{11}$ & 13.51 \\
\hline & 0.36 & $N^{6}$ & 2.82 & $\widetilde{v}^{12}$ & 10.76 \\
\hline & & & & & \\
\hline
\end{tabular}

Note: * denotes percentage. The subscript ave denotes average values. The subscript $w$ denotes the capital weighted average of the real rental rate. 
where $\epsilon$ is the growth rate shock to disembodied technology and $\nu$ is the growth rate shock to embodied technology. The persistence parameter for the disembodied technology process $\left(\rho_{m}\right)$ is equal to 0.31420 ; while the persistence parameter of embodied technology process $\left(\rho_{A}\right)$ is equal to 0.49747 for the GHK decomposition and equal to 0.58146 for the orthogonal (MT) decomposition. Then the aggregate growth rate for the economy is:

$$
\ln G_{t+1}=\ln \left(\frac{\Omega_{t+1}}{\Omega_{t}}\right)=(1-\alpha)^{-1} \ln g_{t+1}+\ln \gamma_{t-T+1}
$$

and its mean, $\bar{G}$, is given by:

$$
\bar{G}=\bar{g}^{\frac{1}{1-\alpha}} \bar{\gamma}
$$

The stochastic model was estimated by using the undetermined coefficients method described in Christiano (2002). For the simulation exercises, we approximate the percent standard deviation of the annual growth rate of output for the U.S. economy over the period 1965-2006 (where the sample length has been selected to match the available wage data) from equations (32) and (33). The percent standard deviation of disembodied technology is equal to $\sigma_{m}=0.00303$. The percent standard deviation of embodied technology is equal to $\sigma_{A, G H K}=0.00410$ for the GHK decomposition and equal to $\sigma_{A, O R T H O}=0.003565$ for the orthogonal decomposition.

To compute the second moments from the simulations in order to compare them with data, we run 5000 replications of length 42 (to match the sample period). The results are displayed in Table 4 for both 3-vintage and 12-vintage capitals model. 
Table 4: Persistence Parameters and Second Moments

\begin{tabular}{cccccc}
\hline \hline \multicolumn{2}{c}{ Second } & US Data & \multicolumn{2}{c}{ 3 Vintage Model } & \multicolumn{2}{c}{12 Vintage Model } \\
Moments & $1965-2006$ & GHK & Orthogonal & GHK & Orthogonal \\
\hline$\rho(C, Y)$ & 0.89 & 0.82 & 0.91 & 0.81 & 0.78 \\
$\rho(I N V, Y)$ & 0.83 & 0.73 & 0.86 & 0.74 & 0.67 \\
$\rho(C, I N V)$ & 0.67 & 0.30 & 0.67 & 0.27 & 0.15 \\
$\rho(N, Y)$ & 0.90 & 0.86 & 0.92 & 0.43 & 0.30 \\
$\rho(\operatorname{Prod}, Y)$ & 0.11 & 0.71 & 0.75 & 0.93 & 0.92 \\
$\rho\left(\right.$ Prod,Prod $\left._{-1}\right)$ & 0.50 & 0.48 & 0.39 & 0.91 & 0.91 \\
$\frac{\sigma_{C}}{\sigma_{Y}}$ & 0.61 & 0.90 & 0.80 & 0.90 & 0.98 \\
$\frac{\sigma_{I N V}}{\sigma_{Y}}$ & 3.31 & 1.22 & 0.97 & 1.40 & 1.49 \\
$\frac{\sigma_{N}}{\sigma_{Y}}$ & 1.06 & 0.73 & 0.74 & 0.33 & 0.35 \\
\hline
\end{tabular}

Note: The symbols $\rho(x, y)$ and $\sigma(x)$ are the correlation coefficient between variables $x$ and $y$, and the percent standard deviation of $x$. The variables listed are real consumption of nondurables and services $(C)$, real business fixed investment $(I N V)$, real GDP $(Y)$, hours of private nonfarm, noninstitutional workers $(N)$, average productivity (Prod), measured as output per manhour $(Y / N)$. The simulated data for $C, I N V, Y$, and Prod are normalized. The data were HP filtered with a smoothing parameter of 100 .

\section{The Effect of Embodied versus Disembodied Tech- nological Progress}

This section reports on exercises designed to examine the effects of disembodied and embodied technological progress. In the first exercise, we focus on the consequences of shifting the overall composition of the sources of growth from the benchmark settings of 60 percent embodied technology-40 percent disembodied technology (TFP) to 100 percent embodied technology. The shift to 100 percent embodied technology growth will make the quality gradient across vintages of capital steepen, thus inducing a reallocation of labor toward the more recent vintage. This gives rise to two opposing effects on the consumption-savings decision. There is a substitution effect that increases the aggregate savings rate and decreases the consumption-output ratio. However, there is also a wealth effect that tends to reduce the saving rate and 
increase the consumption-output ratio. The results indicate that the wealth effect dominates the substitution effect, implying that economies that rely more heavily on embodied technological advance will have lower saving rates, with a higher share of output going to consumption.

In the second set of exercises, we compare the short-run dynamic responses of the economy to a permanent disembodied (TFP) shock versus the response to a permanent shock to embodied technology. Both TFP and embodied technology shocks have the same qualitative responses. On impact, the wealth effect described above dominates the substitution effect. However, in subsequent periods, the substitution effect is stronger. Consequently, there is a consumption boom in the initial period following the shock and this response is followed by a lengthy investment boom. The quantitative responses to the embodied technology shock are significantly stronger than to the TFP shock.

\subsection{Steady State Effects of Changes in the Source of Growth}

In the benchmark steady-state, we set the long-run growth rate at 2.5 percent $(\bar{G}=$ 1.025) with 60 percent attributed to embodied technological progress and 40 percent to disembodied technological progress. In this section, we examine the consequences of shifting all growth to embodied technology $(\bar{\gamma}=1.025)$. We report the results for the 12-vintage capital model (for the 3-vintage capital model, see Marquis and Trehan 2007). The results are compare to the benchmark values in Table 5.

From Table 5, causing 100 percent of long-run growth to come from embodied technological process increases the consumption-output ratio by three-tenths of a percent and decrease the saving rate by six-tenth of a percent. The decrease in the 
Table 5: Steady-State Effects of Changes in Embodied Technology's Share of Growth

\begin{tabular}{|c|c|c|}
\hline Variables & $\begin{array}{c}\text { Benchmark } \\
\bar{\gamma}=1.015\end{array}$ & $\begin{array}{c}\text { Percentage Change } \\
\bar{\gamma}=1.025\end{array}$ \\
\hline Consumption-Output Ratio, $\left(\frac{\tilde{c}}{\widetilde{y}}\right)$ & 0.709 & 0.26 \\
\hline Saving Rate, $\left(\frac{\widetilde{i}}{\widetilde{y}}\right)$ & 0.291 & -0.63 \\
\hline Real Net Rental Rate on $K^{1}, r^{1}$ & 9.50 & $18.45^{*}$ \\
\hline Real Net Rental Rate on $K^{2}, r^{2}$ & 8.97 & $14.78^{*}$ \\
\hline Real Net Rental Rate on $K^{3}, r^{3}$ & 8.45 & $11.01^{*}$ \\
\hline Real Net Rental Rate on $K^{4}, r^{4}$ & 7.95 & $7.09^{*}$ \\
\hline Real Net Rental Rate on $K^{5}, r^{5}$ & 7.47 & $3.01^{*}$ \\
\hline Real Net Rental Rate on $K^{6}, r^{6}$ & 7.00 & $-1.26^{*}$ \\
\hline Real Net Rental Rate on $K^{7}, r^{7}$ & 6.54 & $-5.77^{*}$ \\
\hline Real Net Rental Rate on $K^{8}, r^{8}$ & 6.10 & $-10.54^{*}$ \\
\hline Real Net Rental Rate on $K^{9}, r^{9}$ & 5.67 & $-15.66^{*}$ \\
\hline Real Net Rental Rate on $K^{10}, r^{10}$ & 5.25 & $-21.17^{*}$ \\
\hline Real Net Rental Rate on $K^{11}, r^{11}$ & 4.85 & $-27.17^{*}$ \\
\hline Real Net Rental Rate on $K^{12}, r^{12}$ & 4.46 & $-33.78^{*}$ \\
\hline Share Allocated to Vintage $1, \widehat{x}^{1}$ & 0.0709 & 8.46 \\
\hline Share Allocated to Vintage $2, \widehat{x}^{2}$ & 0.0719 & 7.79 \\
\hline Share Allocated to Vintage $3, \widehat{x}^{3}$ & 0.0731 & 6.84 \\
\hline Share Allocated to Vintage $4, \widehat{x}^{4}$ & 0.0745 & 5.91 \\
\hline Share Allocated to Vintage $5, \widehat{x}^{5}$ & 0.0763 & 4.59 \\
\hline Share Allocated to Vintage $6, \widehat{x}^{6}$ & 0.0784 & 3.19 \\
\hline Share Allocated to Vintage $7, \widehat{x}^{7}$ & 0.0809 & 1.73 \\
\hline Share Allocated to Vintage $8, \widehat{x}^{8}$ & 0.0841 & -0.24 \\
\hline Share Allocated to Vintage $9, \widehat{x}^{9}$ & 0.0881 & -2.38 \\
\hline Share Allocated to Vintage $10, \widehat{x}^{10}$ & 0.0932 & -5.04 \\
\hline Share Allocated to Vintage $11, \widehat{x}^{11}$ & 0.0998 & -8.22 \\
\hline Share Allocated to Vintage $12, \widehat{x}^{12}$ & 0.1088 & -12.13 \\
\hline Hourly Wage Ratio: Vintage $1-12,\left(\frac{\widetilde{v}^{1}}{\widetilde{v}^{12}}\right)$ & 7.31 & $0.85^{* *}$ \\
\hline Hourly Wage Ratio: Vintage $3-12,\left(\frac{\widetilde{v}^{3}}{\widetilde{v}^{12}}\right)$ & 5.34 & $-1.57^{* *}$ \\
\hline Hourly Wage Ratio: Vintage 5-12, $\left(\frac{\widetilde{v}^{5}}{\widetilde{v}^{12}}\right)$ & 3.85 & $-3.41^{* *}$ \\
\hline Hourly Wage Ratio: Vintage $7-12,\left(\frac{\widetilde{v}^{7}}{\widetilde{v}^{12}}\right)$ & 2.73 & $-4.46^{* *}$ \\
\hline Hourly Wage Ratio: Vintage $9-12,\left(\frac{\widetilde{v}^{9}}{\widetilde{v}^{12}}\right)$ & 1.89 & $-4.35^{* *}$ \\
\hline Hourly Wage Ratio: Vintage $11-12,\left(\frac{\widetilde{v}^{11}}{\widetilde{v}^{12}}\right)$ & 1.26 & $-2.28^{* *}$ \\
\hline
\end{tabular}

Note: $*$ is the changes in the percent rates of return and ${ }^{* *}$ is the percentage change of the ratio of hourly of vintage. The output, $\widetilde{y}$, is the normalized output with the salvage capital. 
saving rate is in contrast to the findings of Benhabib and Hobijn (2001) who find that the saving rate rises when the pace of embodied technological progress increases (in a model with vintage capital but a homogeneous labor force). In our model, the higher consumption-output ratio results from the fact that the wealth effect dominates the substitution effect. When all of the growth comes from embodied technological process, the quality gradient of capital steepens leading to a reallocation of labor towards the newest vintage, thus allowing for a more efficient use of the economy's heterogeneous labor supply. Households benefit from long-run growth of embodied technology by realizing a higher income level and an increase in their lifetime utility associated with the consumption-output ratio.

The steepening of the quality gradient due to the more rapid growth of embodied technology increases the real rental rate of the newest vintage of capital and decreases the real rental rate of the oldest vintage. Quantitatively, the percentage changes in rates of return are large. For the newest vintage, the percentage increase in the real rental rate is more than 18 percent. This increase declines as you move to older vintages until you reach vintage six, after which the rates of return decline. The real rental rate on the oldest vintage of capital declines by more than 33 percent.

The steepening of the quality gradient across vintages also induces a shift of human capital toward the latest vintage and away from the oldest vintage. The share of human capital allocated to the newest vintage increases by around 8 percent and the share of human capital allocated to the oldest vintage falls by around 12 percent. Hence those workers shifting to a newer vintage of capital benefit from the increase in real wages that accompanies the higher marginal products of labor that the improved technology provides. However, the average skill level of all worker groups 
falls, tending to depress the wages in each group. As shown in Table 5, only the wages for the workers assigned to the latest vintage will see their wages rise relative to the least skilled group of workers, who are assigned to work with the oldest technology.

\subsection{Comparing the Response of the Economy to Permanent Shocks to Embodied versus Disembodied Technology}

This exercise assumes that growth rate shocks to embodied and disembodied technology contribute equally to the variance of output in the benchmark model. We compare the responses obtained from the 3-vintage capital model and the 12-vintage capital model to see what happens when capital service life changes. We use the persistence parameters from both the GHK and the orthogonal decompositions of productivity to examine the dynamic responses of the economy to these shocks.

\subsubsection{Responses to a Single Technology Shock in 3- and 12-Vintage Mod- els}

There is a trade-off between income and substitution effects for the 3- and the 12-vintage capital models. In the 3-vintage capital model, a permanent shock to disembodied technology increases the consumption-output ratio in the first period, after which the ratio declines and converges to its steady-state value (see top panel of Figure 1). The saving rate thus declines in the first period and then increases thereafter, eventually converging to the steady-state level. (See the middle panel of Figure 1.) Therefore, in response to a disembodied technology shock, the wealth effect dominates the substitution effect in the first period in the 3-vintage capital model as agents can realize a greater utility gain by raising their consumption relatively more 
than they increase their investment in short-lived capital. The results differ for the 12vintage capital model. The consumption-output ratio changes very little in the first period following a permanent shock to disembodied technology, and after a modest decline in the second period, it eventually converges to the long-run steady-state. (See the top panel of Figure 2.) Therefore, in this model with long-lived capital, the benefit to saving and investing is greater than for the model with short-lived capital, and so the wealth effect does not dominate the substitution effect.

These results imply that the pace of embodied technical change can affect how an economy reacts to disembodied technology shock through the effect it has on the number of vintages in use. An economy with rapid improvements in embodied technology-that cause capital to become obsolete relatively quickly-will experience a consumption boom in the first period following a permanent disembodied technology shock, but will see little change in investment. On the other hand, an economy with relatively slow improvements in technology will not see a big effect on the consumption-savings decision in the initial period, but will experience a modest investment boom in subsequent periods. As discussed in Section 4.3 below, the degree of persistence in the shocks affects how slowly these effects dissipate.

A permanent embodied technology shock leads to an investment boom in both the 3-vintage and the 12-vintage models. (Refer again to Figures 1 and 2.) This investment boom is more pronounced and more persistent in the model with longlived capital where technological progress is slower. Differences emerge in the initial period between the two decompositions of embodied technology. The wealth effect appears to be stronger with the orthogonal measure than with the GHK measure. In the 3-vintage capital model, there is a modest consumption boom indicated for the 
Figure 1: Responses to a Technology Shock in 3 Vintage Model
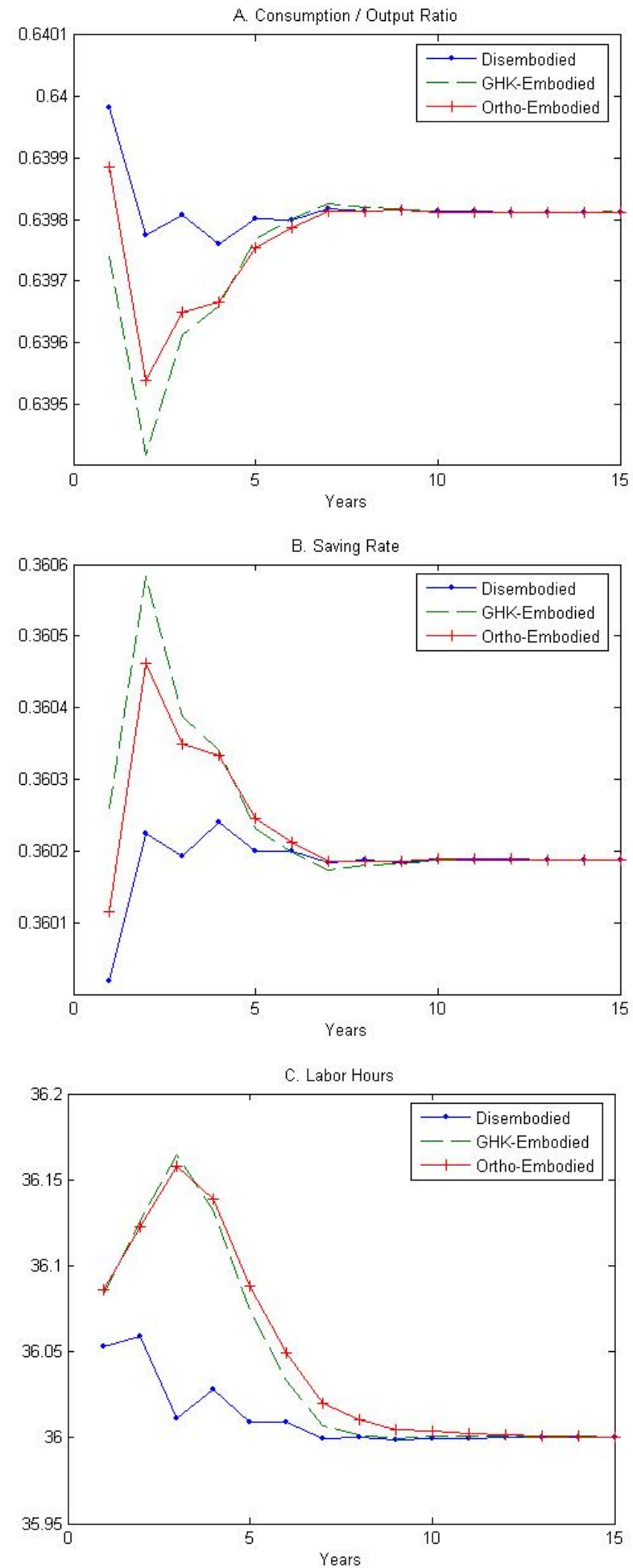
Figure 2: Responses to a Technology Shock in 12 Vintage Model
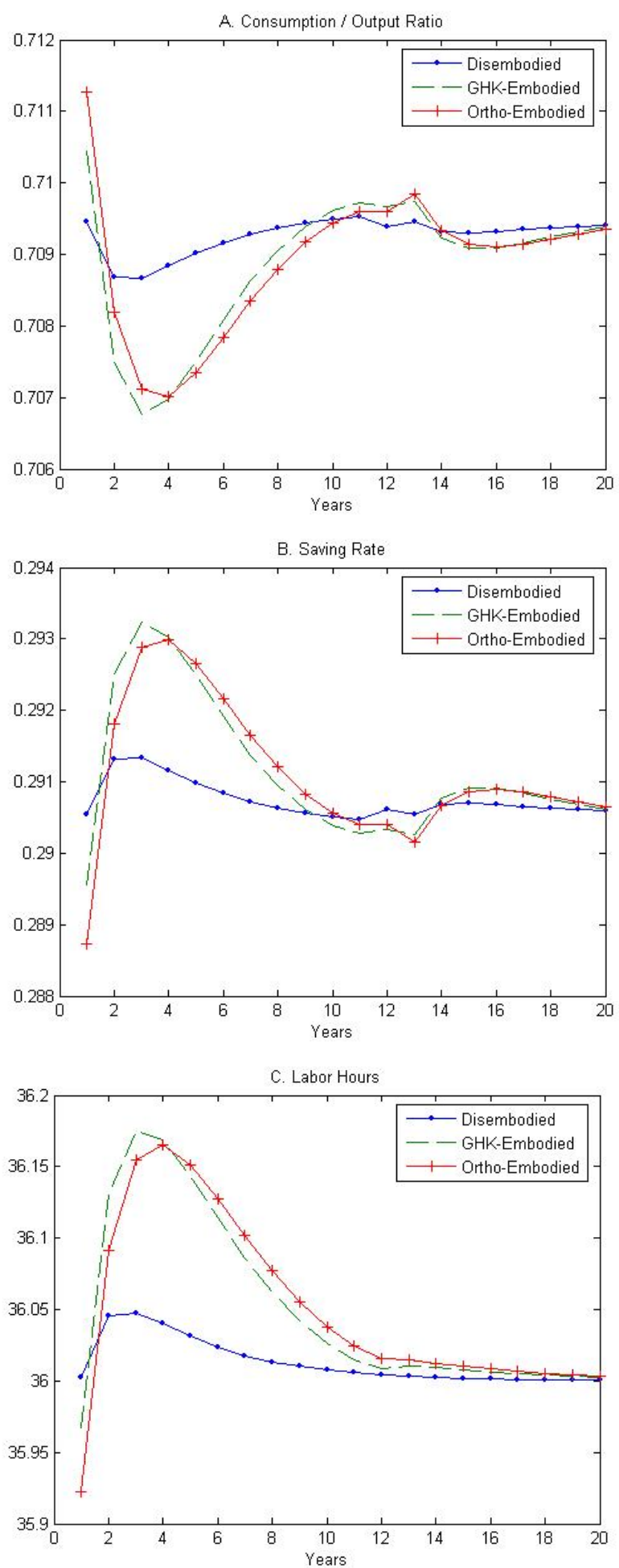
orthogonal measure and a modest investment boom indicated for the GHK measure in the first period. Both measures predict a consumption boom in the 12-vintage capital model in the initial period, but the effect is more pronounced for the orthogonal measure.

The bottom panel of Figure 1 shows that in the 3-vintage model (where capital improves more rapidly), total labor hours worked increase in response to either a permanent embodied or disembodied shock, although the response is much stronger and more persistent for the embodied shock. Both impulse response functions display a hump-shaped response, although it is much more pronounced for the embodied technology shock. In the case of the 12-vintage capital model (where capital is improving less rapidly), there is less of an incentive to increase work effort at once, as the benefits from the shock die out more slowly due to the longer duration required for the economy to absorb the shock. In this case, the initial response to either the disembodied or embodied shock is negative, as the wealth effect dominates the wealth effect in the labor-leisure decision. However, by the second period the labor response is positive, with the well-defined hump-shaped response stronger for the embodied technology shock.

Figures 3 and 4 display how the allocation of labor across vintages changes in response to technology shocks in the two models. As expected, significant differences emerge in the response to a disembodied versus an embodied technology shock. In response to an embodied shock, labor gets allocated toward the newest vintage and away from the oldest vintage in order to realize greater efficiency in the use of the economy's human capital. To examine how the shift in human capital proceeds as the technology is dispersed through the economy, refer to the panel $\mathrm{C}$ of Figure 4, which 
displays the impulse response function for the group of workers assigned to work with the eighth oldest vintage of capital. As time passes and the new technology associated with the shock ages, access to that technology proceeds to worker groups whose skill levels are ever closer to those of worker group eight. During this period, workers from lower skill levels are shifted in growing numbers (more hours) toward the more recent vintages, and worker group eight contracts. The process continues until the new technology has aged sufficiently that workers in group eight have access to it. At that point, group eight attracts lower-skilled workers and the allocation to group eight jumps. As the technology diffuses to even lower skilled workers, labor allocation to group eight begins to fall back. After $T$ periods, the new technology has been fully diffused throughout the production process for the economy as a whole and labor allocation to group eight is back to steady state. ${ }^{6}$

\subsubsection{Responses to a Sequence of Shocks in the 3 and 12 Vintage Models}

In this exercise, we examine the response of the models to a sequence of positive technology shocks. Some have argued that such an event took place in the late 1990s in the United States, and that these shocks created an investment boom (as we have described it). We assume a sequence of five shocks to each type of technology. Figures 5 and 6 display the results for the 3 -vintage and 12-vintage models respectively. As expected, apart from the first period, the sequence of five embodied technology shocks creates an investment boom with agents increasing their saving rate; however, the amplitude of the response is much greater than it was in the single shock case. For

\footnotetext{
${ }^{6}$ We note that over time all workers benefit by the improved technology. A feature that is consistent with the historical experience of secular increases in real wages at all skill levels. This empirical fact is not predicted by models that feature capital-skill complementarities.
} 
Figure 3: Labor Re-allocation in Response to a Technology Shock in 3 Vintage Model
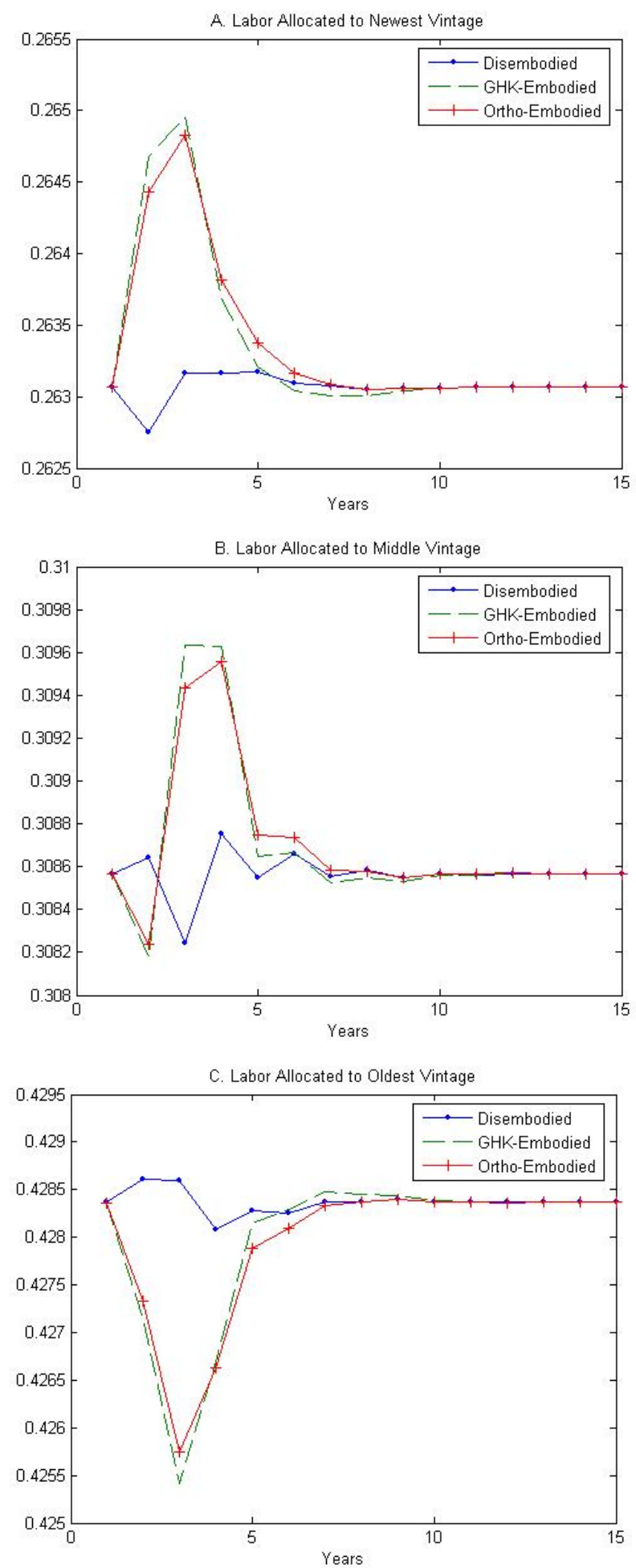
Figure 4: Labor Re-allocation in Response to a Single Technology Shock in 12 Vintage Model
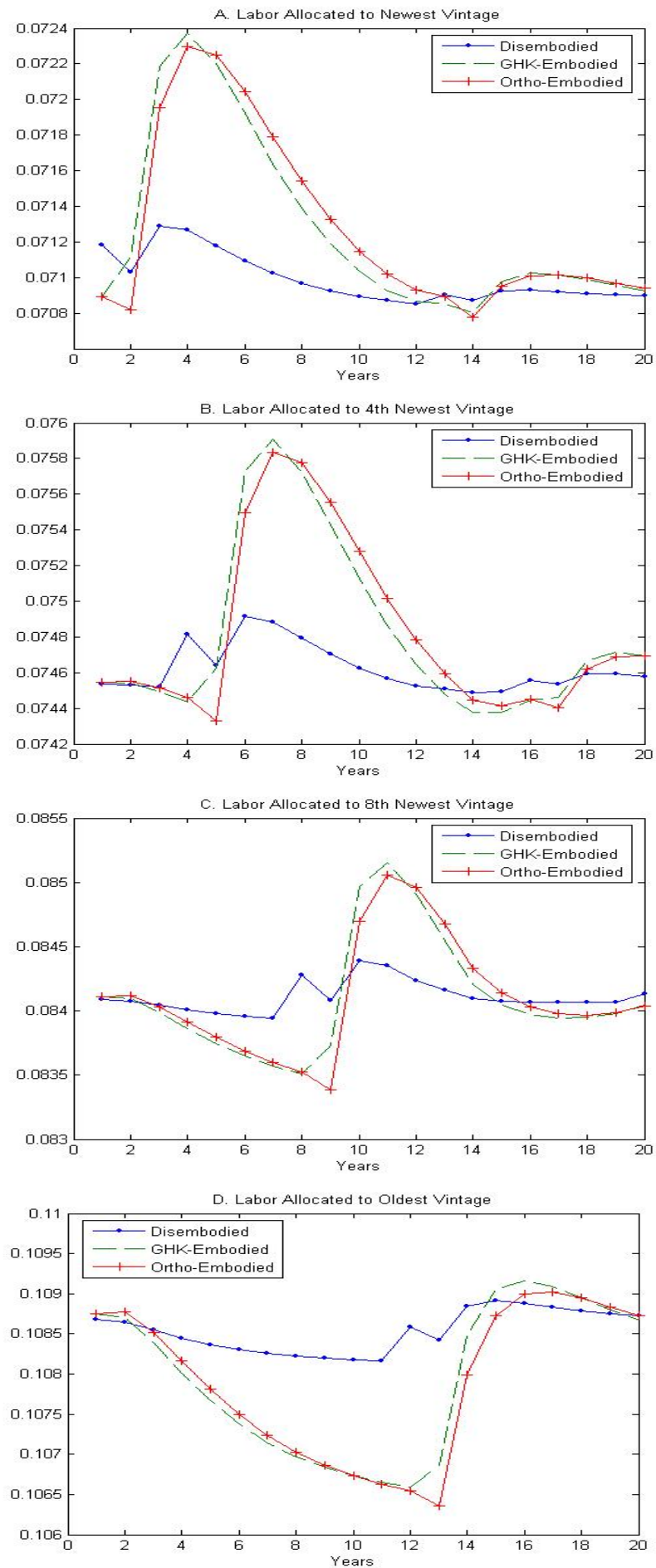
the sequence of five disembodied shocks, a consumption boom occurs in the 3-vintage model that lasts five periods (years) with little evidence of a subsequent investment boom. However, in the 12-vintage model, there is a clear humped-shaped investment boom, with little evidence of a subsequent consumption boom.

These results for disembodied technology shocks suggest that the service life of capital equipment significantly affects the characteristics of disembodied-technology driven business cycles. In particular, if this service life has decreased in recent years (as seems consistent with the BEA data on capital equipment described in the introduction), then disembodied shocks of a given size would be associated with a lower variance of investment and output than before. This would tend to reduce the volatility of output in recent years. But output may have become more volatile if the technology shocks of the 1990s were better characterized as improvements in embodied technology.

The data from 1991 to 1999 suggests an increase in the investment-output ratio. ${ }^{7}$ In terms of our model's predictions, the shift to shorter-lived capital is dominated by the preponderance of improved technology in capital equipment.

The last panel of Figures 5 and 6 show how labor hours respond to the sequences of technology shocks. In both the 3- and 12-vintage models, labor hours increase in response to both kinds of shocks, but the responses to embodied technology shocks are much larger than the responses to the disembodied shocks. The effects of the shocks persist longer in the 12-vintage model than in the 3 -vintage model.

\footnotetext{
${ }^{7}$ Using the output of consumer nondurables and services from the NIPA accounts to represent consumption and private fixed investment from the NIPA accounts, we find that from 1991 to 1999 , private fixed investment grew by an average of 6.6 percent per year while consumption grew by 3.3 percent, implying an increase in the investment-output ratio.
} 
Figure 5: The Effect of A Sequence of Technology Shocks in the 3 Vintage Model
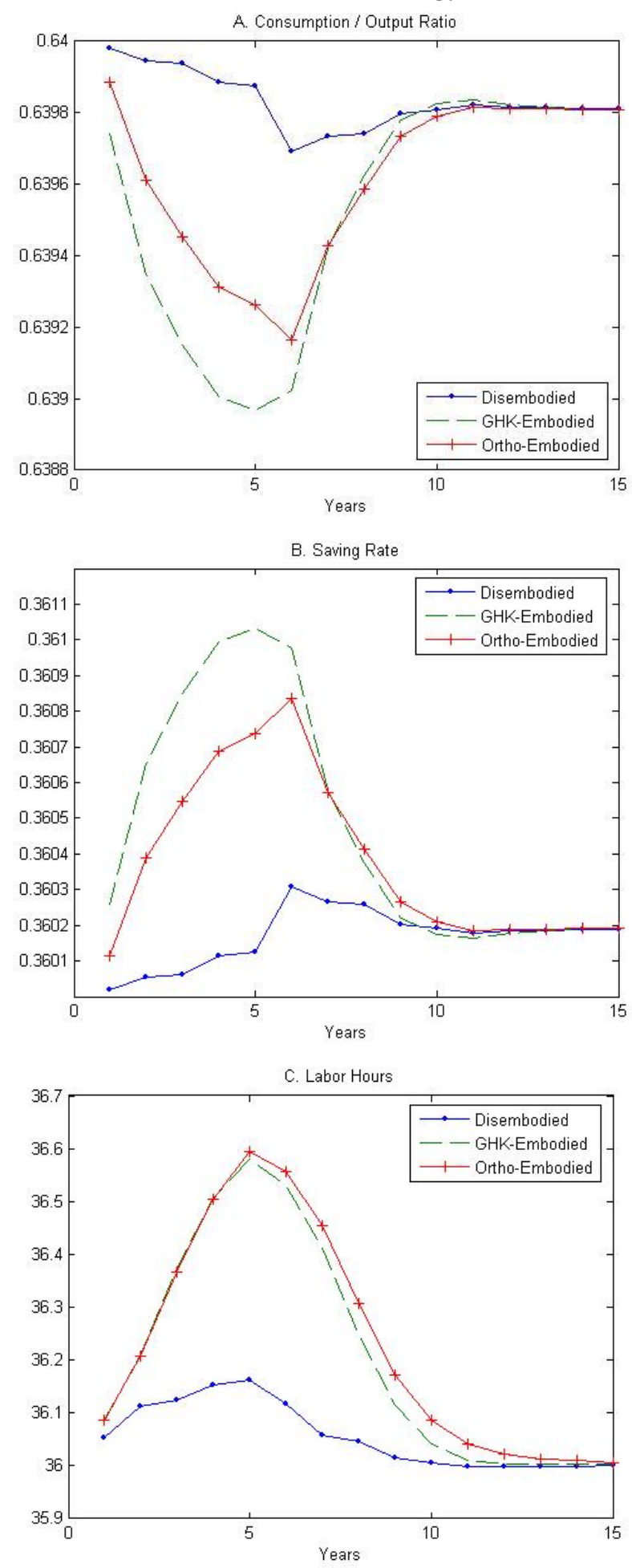
Figure 6: The Effect of A Sequence of Technology Shocks in the 12 Vintage Model
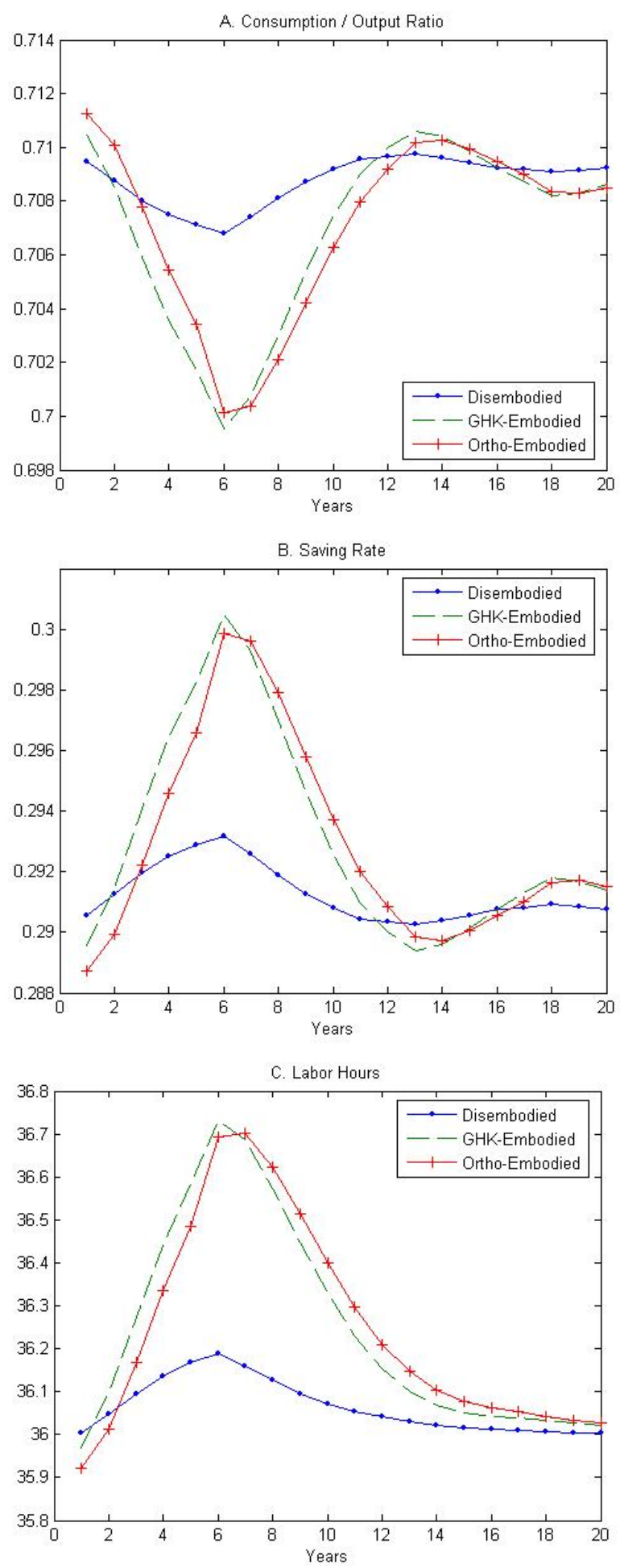


\subsection{The Effects of a Change in the Persistence of the Tech- nology Shock}

In this exercise, we look at the effects of varying the persistence of the shock processes. We show the results for the 12 vintage model. (The responses in the 3vintage capital model are similar, though there are differences in amplitude.) We use the standard deviation of the technology shock equal to $0.0035^{8}$ and set the persistence parameter to equal one of three values: $0,0.5$, and 0.9 for both the disembodied and embodied technology shock. The results are shown in Figure 7 .

When the persistence parameter equals 0 , both disembodied and embodied technology shocks lead to an investment boom, as a short-lived shock means that the substitution effect dominates the wealth effect. The economy will respond in the same direction to both disembodied and embodied technology shock. A positive technology shock increases the marginal product of vintage capital, but in different ways. The disembodied technology shock will increase the marginal product of all vintages, while the embodied technology shock increases the marginal product of only the latest vintage. However, the benefit of the embodied technology shock is realized over time as the capital ages. This feature induces a larger response of agents to embodied technology shocks than to disembodied technology shocks.

As we increase the value of the persistence parameter to 0.5 and then to 0.9 , the wealth effect comes to dominate the substitution effect. With 0.5 persistence, the wealth effect will dominate the substitution effect in the first period of the technology shock. The consumption boom will occur in the first period. With 0.9 persistence,

\footnotetext{
${ }^{8}$ The roughly average of the standard deviation in both disembodied and embodied technology: $\sigma_{m}=0.00303, \sigma_{A, G H K}=0.00410$, and $\left.\sigma_{A, O R T H O}=0.003565\right)$
} 
Figure 7: The Effect of Varying the Persistence of the Technology Shocks
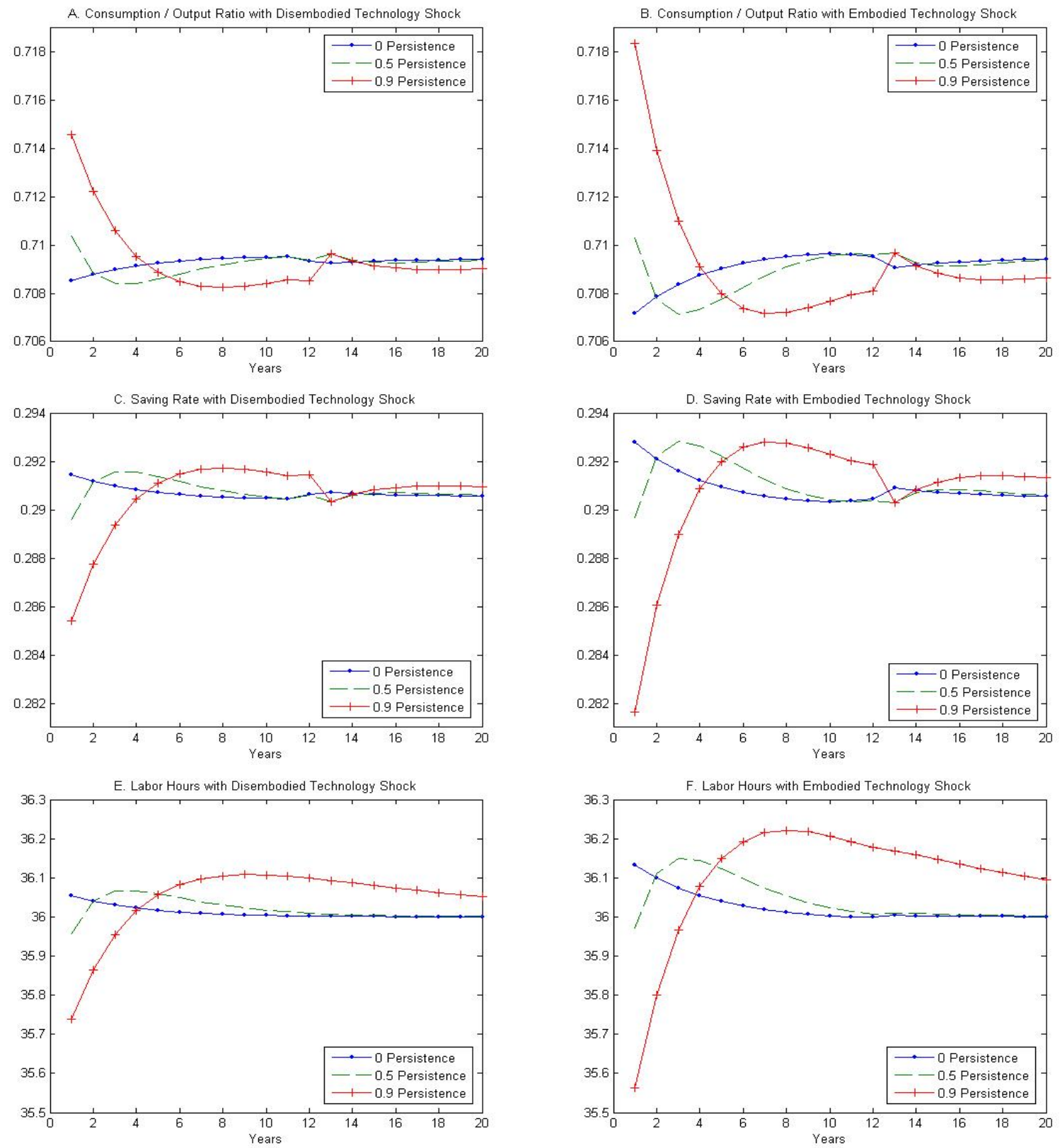
the consumption boom lasts longer. Hence the value of the persistence parameter plays a role in determining whether the economy experiences a consumption boom or an investment boom. Comparing the results from the 3 and 12 vintage models, the value of the persistence parameter at which the economy changes from an investment boom to a consumption is always lower in the 3 -vintage model than in the 12-vintage

capital model. For the same persistence of the technology shock, agents benefit more from investing in the 12-vintage model than in the 3 -vintage model.

As the substitution effect dominates the wealth effect at first, labor hours initially will decrease in response to both disembodied and embodied technology shocks (see Figure $7 \mathrm{E}$ and $7 \mathrm{~F}$ ). After that, the substitution effect will dominate the wealth effect, and labor hours will increase; so will the saving rate. The responses to the embodied technology shock are larger (more volatile) than to the disembodied technology shock, because the marginal return to investing in the newest vintage capital is higher in the case of the embodied technology shock than in the case of the disembodied technology shock. Hence both the number of vintages of capital and the amount of persistence in the technology shock can alter the way in which the economy responds to the technology shock.

\section{Conclusions}

This paper examines how the economy responds to embodied and disembodied technology shocks. Using data on productivity growth over the 1965-2006 period, we have shown that the two different kinds of technology shocks lead to different responses in consumption and investment. The number of vintages of the capital 
good and the sequence as well as the persistence of the technology shock can make a difference. In the case of an embodied technology shock in the 3-vintage model, the substitution effect tends to dominate the wealth effect as long as the shock is not very long lived, leading to an investment boom. But a consumption boom results from a disembodied technology shock, as the wealth effect dominates the substitution effect. The response of labor hours depends on which of the effects dominates. This is reinforced by the production process; when investment goes up, so do labor hours.

Usually, the embodied technology shock leads to responses that are more volatile (higher magnitude) when compared with the responses to the disembodied technology shock. The embodied shock leads to higher volatility because a single positive shock to embodied technology raises the productivity of the latest vintage of capital relative to past vintages; since the only way to benefit from this higher productivity is to have more of the latest vintage, investment will go up. It is the opposite with the disembodied technology shock. The disembodied technology shock will affect all vintages of capital equally, so it does not motivate agents to invest more in the latest vintage capital. The number of vintages also turns out to be a determinant of how the economy responds to a technology shock, with the economy that has more vintages of capital responding more to a given technology shock than an economy that has fewer vintages.

These two factors have opposite implications for the volatility of economic fluctuations in recent decades. If, as seems likely, the service life of capital has been decreasing (which means that the number of vintages in use at any point has been decreasing) with embodied technical progress, the economy should be becoming less volatile over time. In particular, the economy should react less to a given shock to 
disembodied technology. But if embodied technology shocks become more commonas is likely to have been the case during the 1990s-the economy is likely to become more volatile. It is worth exploring which of these effects will dominate in future research. 


\section{References}

Abowd, J. M., P A. Lengermann and K. J. McKinney. (2002). "The Measurement of Human Capital in the U.S. Economy," U.S. Census Bureau LEHD Program Technical paper No. TP-2002-09.

Christiano, L. J.(2002). "Solving Dynamic Equilibrium Models by a Method of Undetermined Coefficients," Computational Economics, Vol 20, No.1-2, 21-55.

Cummins, J. G. and G. L. Violante (2002). "Investment-Specific Technical Change in the United States (1947-2000): Measurement and Macroeconomic Consequences," Review of Economic Dynamics, Vol. 5, 243-284.

Fisher, J. (2002). "Technology Shocks Matter," Working Paper Series WP-02-14, Federal Reserve Bank of Chicago.

Glichrist S. and Williams J. C. (2000). "Putty-Clay and Investment: A Business Cycle Analysis," Journal of Political Economy, Vol. 108, No. 5, 928-960.

Greenwood, J., Z. Hercowitz and P. Krusell (1997). "Long-Run Implications of Investment-Specific Technological Change," American Economic Review, Vol. 87, No. 3, 342-362.

Greenwood, J., Z. Hercowitz and P. Krusell (2000). "The Role of Investment-Specific Technological Change in Business Cycle," European Economic Review, 91-115.

Jovanovic, B. (1998). "Vintage Capital and Inequality," Review of Economic Dynamics, Vol. 1, 497-530. 
Krusell, P., L. E. Ohanian, J. V. Rios-Rull and G. L. Violante (2000). "Capital-Skill Complementarity and Inequality: A Macroeconomic Analysis," Econometrica, Vol. 68, No. 5, 1029-1053.

Lucas, R. E., Jr. (1980). "Equilibrium in a Pure Currency Economy," Economic Inquiry, Vol 18, No. 2, 203-220.

Marquis, M. H. and B. Trehan (2008). "On Using Relative Prices to Measure CapitalSpecific Technological Progress," Journal of Macroeconomics, Vol 30, No. 4, 13901406.

Marquis, M. H. and B. Trehan (2007). "Productivity Shocks in a Model with Vintage Capital and Heterogeneous Labor," Center for the Study of Innovation and Productivity, Federal Reserve Bank of San Francisco, Working Paper 2007-06.

Mehra, R. and E. C. Prescott (2008). "The Equity Premium: ABCs," The Handbook of the Equity Risk Premium, Elsevier, Amsterdam, 1-36.

Oliner, S.D., D.E. Sichel and Kevin Stiroh (2007). "Explaining a Productive Decade," Brookings Papers on Economic Activityvol. 1, pp. 81-137.

Wilson, D. (2001). "Capital-Embodied Technical Change: Measurement and Productivity Effects," Ph.D. Dissertation, University of Maryland, May. 